\title{
TLC determination of some flavanones in the buds of different genus Populus species and hybrids
}

\author{
LORETTA POBŁOCKA-OLECH \\ PIOTR MIGAS \\ MIROSŁAWA KRAUZE-BARANOWSKA* \\ Department of Pharmacognosy \\ with Medicinal Plants Garden \\ Faculty of Pharmacy with Subfaculty \\ of Laboratory Medicine \\ Medical University of Gdańsk \\ 80-416 Gdańsk, Poland
}

Accepted January 18, 2018

Published online February 19, 2018

\begin{abstract}
Flavonoids in the buds of eight Populus species and hybrids were detected and compared with the aid of an optimized TLC method. Separation of 17 flavonoid aglycones belonging to different groups, namely, flavones, flavonols, flavanones and flavanonols, previously described as constituents of poplar buds, was performed on silica gel plates using a hexane/ ethyl acetate/formic acid (60:40:1.3, V/V/V) mixture as the mobile phase. Pinocembrin and pinostrobin were found in the majority of analyzed poplar buds. For quantitative analysis of both compounds, two TLC evaluation modes, densitometric and videodensitometric, were compared and the established methods were validated. Concentrations of flavanones in some extracts differed slightly or significantly due to the analyzed plant matrix complexity and the TLC evaluation mode applied. Poplar buds rich in flavanones originated from $P$. × canadensis 'Robusta' (1.82 and $2.23 \mathrm{~g}$ per $100 \mathrm{~g}$, resp.) and P. balsamifera (1.17 and $2.24 \mathrm{~g}$ per $100 \mathrm{~g}$, resp.).
\end{abstract}

Keywords: poplar buds, pinocembrin, pinostrobin, TLC, videodensitometry, densitometry

Besides leaves and bark, poplar buds (Populi gemma) are herbal remedies originating from different species of the genus Populus (1). Buds collected from Populus nigra, P. candicans (syn. P. gileadensis) or P. balsamifera (syn. P. tacamahaca) in Great Britain are referred to as Balm of Gilead, which is used as an expectorant, stimulant, antipyretic and analgesic remedy (1). On the other hand, the German Commission E Monograph (2) listed superficial skin injuries, external hemorrhoids, chilblains and sunburns as therapeutic indications for Populi gemma. Some recent studies of pharmacological activities of poplar buds have demonstrated antioxidant, anti-inflammatory, cardiovascular and hepatoprotective effects (3-5). Considering the similarities of chemical composition, some authors suggested that extracts of poplar buds could be a substitute for propolis in prevention and treatment of inflammatory diseases (4). Bud exudates of poplars are the main sources of propolis processed by honeybees (4).

Flavonoids are the main group of bioactive compounds in the buds of poplars belonging to the Aigeiros and Tacamahaca sections (6). In contrast, cinnamic acid derivatives are

\footnotetext{
*Correspondence; e-mail: krauze@gumed.edu.pl
} 
major compounds in the Leuce and Leucoides sections (6). Major flavonoid constituents are chrysin, galangin and pinocembrin, which are usually accompanied with pinostrobin, tectochrysin and pinobanksin-3-acetate (6). Furthermore, many other compounds were discovered mainly by the GC-MS method (7-11). GC separation of flavonoids is time-consuming due to the necessary sample derivatization before analysis. There are only a few studies focusing on the flavonoid content determination in Populus buds $(3,4,7,8,12,13)$. Flavonoids can play an important role in the pharmacological effects of poplar buds in terms of their antioxidant and anti-inflammatory properties. Among Populus constituents, two flavanones, pinostrobin and pinocembrin, revealed interesting antioxidant and antiinflammatory activities $(14,15)$.

The aim of the current study was to elaborate the conditions of TLC determination of flavonoids in the buds of most popular species and hybrids of the genus Populus in Poland, namely, $P$. alba, $P$. tremula (from section Leuce), $P$. nigra 'Italica', $P$. $\times$ canadensis 'Robusta', $P$. $\times$ canadensis 'Marilandica' (from section Aigeiros) and P. balsamifera, $P$. candicans, $P$. simonii (from Tacamahaca) (6). Moreover, two modes of TLC evaluation, videodensitometric and densitometric, were compared for the purpose of quantitative analysis of pinocembrin and pinostrobin.

\section{EXPERIMENTAL}

\section{Chemicals}

All solvents were of analytical grade. Ethyl acetate and methanol were obtained from $\mathrm{POCH}$ (Poland), hexane, formic acid, aluminium chloride and methanol were from Merck (Germany).

Galangin, genkwanin, eriodictyol, isorhamnetin, luteolin, tectochrysin, chrysin 5,7-dimethylether, pinocembrin 5,7-dimethylether, pinocembrin and pinostrobin were purchased from Extrasynthèse (France), apigenin, kaempferol, quercetin and myricetin from Fluka (Switzerland), chrysin and pinobanksin from Sigma (USA) and naringenin from Koch-Light (UK). The standards were dissolved in methanol $\left(0.5 \mathrm{mg} \mathrm{mL}^{-1}\right)$.

\section{Plant material}

Buds of the following Populus species and varieties: P. alba L., P. tremula L., P. nigra 'Italica' Moench., P. × canadensis 'Robusta' Schn., P. × canadensis 'Marilandica' Bosc., P. balsamifera L., P. candicans Aiton, P. simonii Carr., were collected from trees growing in the city of Gdańsk in March 2012 (Poland). Plant material was botanically classified by a taxonomist of the Medicinal Plants Garden of the Medical University of Gdańsk (Poland). Voucher specimens were deposited in the Department of Pharmacognosy of the Medical University of Gdańsk, Poland.

\section{Sample preparation}

Dried buds of poplars $(1 \mathrm{~g})$ were manually crushed and then extracted three times with methanol $\left(30 \mathrm{~mL}, 60^{\circ} \mathrm{C}\right)$ on a magnetic stirrer $(45 \mathrm{~min})$. The obtained extracts were combined and evaporated to dryness and then dissolved in methanol $(20 \mathrm{~mL})$. Three parallel samples of each extract were prepared. 


\section{Thin-layer chromatography}

TLC experiments were carried out on $10 \times 20 \mathrm{~cm}$ TLC Si 60 plates (Merck) with the hexane/ethyl acetate/formic acid (60:40:1.3, V/V/V) mobile phase in a saturated Twin Trough Chamber (Camag, Switzerland) for $10 \mathrm{~min}$.

Standard solutions and samples were applied as 6- $\mathrm{mm}$ bands, $10 \mathrm{~mm}$ from the bottom edge of the plates, with a Desaga AS-30 sample applicator (Germany). The plates were developed to a distance of $8 \mathrm{~cm}$ at room temperature.

Video-densitometric analysis was possible at $366 \mathrm{~nm}$ after derivatization by a specific reagent for flavonoids, $2 \%$ solution of $\mathrm{AlCl}_{3}$ in methanol, using a TLC Visualizer (Camag). Densitometric measurements were performed employing a CD-60 densitometer (Desaga) in the absorbance mode at $290 \mathrm{~nm}$, without derivatization and in fluorescence mode at 310 $\mathrm{nm}$, with a filter at $\lambda=370 \mathrm{~nm}$ after derivatization. Optimal parameters of densitometric analysis - wavelength and filter position were selected on the basis of standard spot scanning employing the multi-wavelength scan function.

Stock standard solutions of analyzed flavonoids were prepared in methanol $\left(0.5 \mathrm{mg} \mathrm{mL}^{-1}\right)$. Working solutions of pinocembrin and pinostrobin were: $0.1,0.2,0.3,0.4,0.5,0.6 \mathrm{mg} \mathrm{mL}^{-1}$ for densitometric analysis at $290 \mathrm{~nm}$ and $0.125,0.2,0.275,0.35,0.425,0.5 \mathrm{mg} \mathrm{mL}^{-1}$ for videodensitometric and densitometric determination after reaction with $2 \% \mathrm{AlCl}_{3}$. The calibration curve was constructed by plotting the peak area (y) against the concentration of each standard solution $(\mathrm{x})$.

\section{Method validation}

Validation parameters were estimated according to ICH rules (16). They included specificity, precision, detection $(L O D)$ and quantification $(L O Q)$ limits, linearity, accuracy and robustness (Tables I and II).

Specificity of the method was confirmed by comparing the $h R_{\mathrm{f}}\left(R_{\mathrm{f}} \times 100\right)$ values and UV spectra of the standards and flavanones observed in investigated samples.

Instrument precision was checked by repeated scanning of the same spot of pinocembrin and pinostrobin (700 ng), seven times, and was expressed as RSD (\%) (Table I).

Repeatability of the method was determined by analyzing $700 \mathrm{ng} \mathrm{spot}^{-1}$ of standard solutions of pinocembrin and pinostrobin, resp., after application on the TLC plate $(n=7)$ and was expressed as RSD (Table I). Intra-day precision was determined by analyzing seven spots (700 ng) of pinocembrin and pinostrobin per plate on three TLC plates (Table I). Inter-day precision was studied by analyzing seven spots (700 ng) of standard solutions per plate on three consecutive days (Table I).

Accuracy of the method was established by performing a recovery study using the standard addition method. The pinocembrin and pinostrobin standards were added to the samples of Populus alba buds at three levels (80,100 and $120 \%$ ) and each was extracted and analyzed as described for the assay (Table I).

Robustness of the method was tested by small variations in the mobile phase composition and changes in saturation time of the chamber. It was assessed for $700 \mathrm{ng}$ of pinocembrin and pinostrobin per band (Table II). 
L. Pobłocka-Olech et al.: TLC determination of some flavanones in the buds of different genus Populus species and hybrids, Acta Pharm. 68 (2018) 199-210.

Table I. Validation data for determination of pinocembrin and pinostrobin by TLC

\begin{tabular}{|c|c|c|c|c|c|c|}
\hline \multirow[b]{2}{*}{$\begin{array}{l}\text { Validation } \\
\text { parameter / method }\end{array}$} & \multicolumn{3}{|c|}{ Pinocembrin } & \multicolumn{3}{|c|}{ Pinostrobin } \\
\hline & 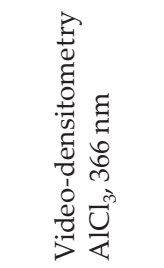 & 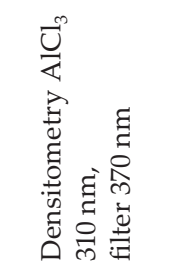 & 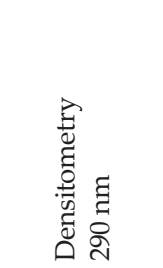 & 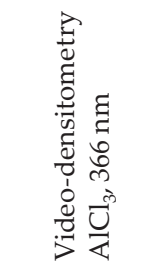 & 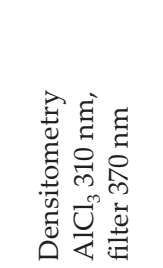 & 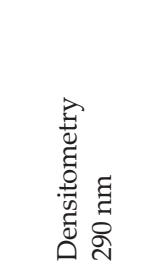 \\
\hline $\begin{array}{l}\text { LOD } \\
\left(\mathrm{mg} \mathrm{mL}^{-1}\right)\end{array}$ & 0.038 & 0.04 & 0.033 & 0.038 & 0.04 & 0.033 \\
\hline $\begin{array}{l}\mathrm{LOQ} \\
\left(\mathrm{mg} \mathrm{mL}^{-1}\right)\end{array}$ & 0.12 & 0.125 & 0.1 & 0.1 & 0.125 & 0.1 \\
\hline $\begin{array}{l}\text { Range } \\
\left(\mathrm{mg} \mathrm{mL} L^{-1}\right)\end{array}$ & $0.125-0.5$ & $0.125-0.5$ & $0.1-0.6$ & $0.125-0.5$ & $0.125-0.5$ & $0.1-0.6$ \\
\hline \multicolumn{7}{|l|}{ Linearity } \\
\hline Slope \pm RSD (\%) & $76.55 \pm 19.4$ & $3.36 \pm 15.5$ & $2.96 \pm 3.7$ & $73.60 \pm 15.0$ & $2.09 \pm 41.6$ & $1.97 \pm 5.6$ \\
\hline Intercept \pm RSD (\%) & $22475 \pm 12.8$ & $162.03 \pm 60.6$ & $501.32 \pm 2.8$ & $13775 \pm 8.1$ & $60.07 \pm 41.7$ & $180.77 \pm 29.2$ \\
\hline$R^{2}$ & 0.9959 & 0.9978 & 0.9971 & 0.9952 & 0.9974 & 0.9989 \\
\hline $\begin{array}{l}\text { Instrumental } \\
\text { precision (RSD, \%) }\end{array}$ & 3.6 & 3.7 & 3.4 & 3.2 & 3.5 & 3.5 \\
\hline $\begin{array}{l}\text { Intra-day assays } \\
(\mathrm{RSD}, \%)^{\mathrm{a}}\end{array}$ & 4.7 & 3.9 & 3.3 & 3.1 & 3.7 & 4.0 \\
\hline $\begin{array}{l}\text { Inter-day assays } \\
(\mathrm{RSD}, \%)^{\mathrm{a}}\end{array}$ & 4.4 & 4.4 & 2.8 & 4.4 & 4.3 & 2.3 \\
\hline Recovery \pm RSD $(\%)^{b}$ & $95.2 \pm 1.7$ & $95.4 \pm 1.9$ & $95.1 \pm 1.6$ & $93.4 \pm 1.7$ & $93.3 \pm 1.5$ & $93.3 \pm 1.9$ \\
\hline
\end{tabular}

${ }^{\mathrm{a}} n=9,{ }^{\mathrm{b}} n=3$

Table II. Robustness testing of the videodensitometric TLC method

\begin{tabular}{lccc}
\hline Factor & Level of changes & $\begin{array}{c}\text { Pinocembrin } \\
\text { RSD (\%) }\end{array}$ & $\begin{array}{c}\text { Pinostrobin } \\
\text { RSD (\%) }\end{array}$ \\
\hline \multirow{2}{*}{ Mobile phase composition $(V / V / V)$} & $59: 41: 1.3$ & 8.6 & 4.3 \\
& $60: 40: 1.3$ & 3.9 & 2.8 \\
Time of saturation of chamber & $61: 39: 1.3$ & 11.0 & 9.3 \\
(min) & 7 & 2.5 & 3.6 \\
& 10 & 4.0 & 2.8 \\
\hline
\end{tabular}




\section{Statistical analysis}

The mean difference between pinocembrin and pinostrobin concentrations was established by one-way analysis of variance (ANOVA), followed by Tukey's multiple comparison tests. Differences were considered significant at $p<0.05$. All statistical analyses were performed using Statistica 12 software (StatSoft, Poland).

\section{RESULTS AND DISCUSSION}

Preliminary TLC and HPTLC separations were carried out using a standard mixture comprising 17 flavonoid aglycones, decribed as constituents of poplar type propolis, that is, six flavones (apigenin, luteolin, genkwanin, chrysin, chrysin 5,7-dimethylether, tectochrysin), five flavonols (galangin, isorhamnetin, kaempferol, quercetin, myricetin), five flavanones (eriodictyol, naringenin, pinocembrin, pinostrobin, pinocembrin 5,7-dimethylether) and one flavanonol (pinobanksin). Optimization of chromatographic separation from methanolic extracts of Populus buds was performed by testing systems previously used for botanical classification of propolis (Table III) (7-10, 17).

The best resolution was achieved on TLC silica gel plates with the use of the mobile phase hexane/ethyl acetate $(60: 40, V / V)(9)$, but the spots of compounds were fuzzy. Addition of formic acid in $1.3 \%$ concentration and saturation of twin trough chamber with the mobile phase within 10 min was needed to improve the shape of spots and increase the TLC separation efficiency (Fig. 1).

Good correlation $(R>0.995)$ between the spectra of standards and pinocembrin and pinostrobin samples indicated that the method was specific.

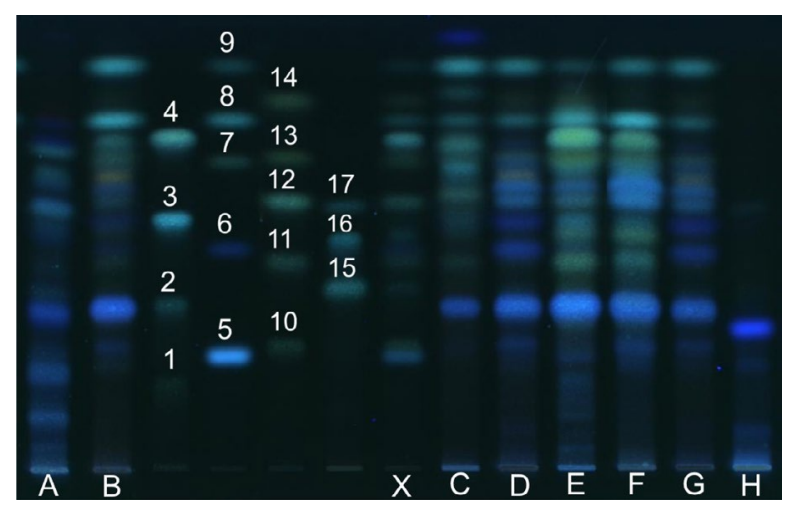

Fig. 1. Video-densitogram of TLC separation (silica gel $60 \mathrm{~F}_{254}$, hexane/ethyl acetate/formic acid $\left.(60: 40: 1.3, V / V / V), 2 \% \mathrm{AlCl}_{3}, \mathrm{UV} \lambda=366 \mathrm{~nm}\right)$ of flavonoid standards and methanolic extracts of poplar buds: A - P. tremula, B - P. × canadensis 'Robusta', C - P. balsamifera, D - P. nigra 'Italica', E - P. $\times$ canadensis 'Marilandica', F - P. simonii, G - P. candicans, H - P. alba, X - the mixture of 17 standards. Key to the spots: 1 - myricetin, 2 - quercetin, 3 - kaempferol, 4 - galangin, 5 - chrysin 5,7-dimethylether, 6 pinocembrin 5,7-dimethylether, 7 - pinobanksin, 8 - pinocembrin, 9 - pinostrobin, 10 - luteolin, 11 - apigenin, 12 - genkwanin, 13 - chrysin, 14 - tectochrysin, 15 - eriodictyol, 16 - isorhamnetin, 17 naringenin. 


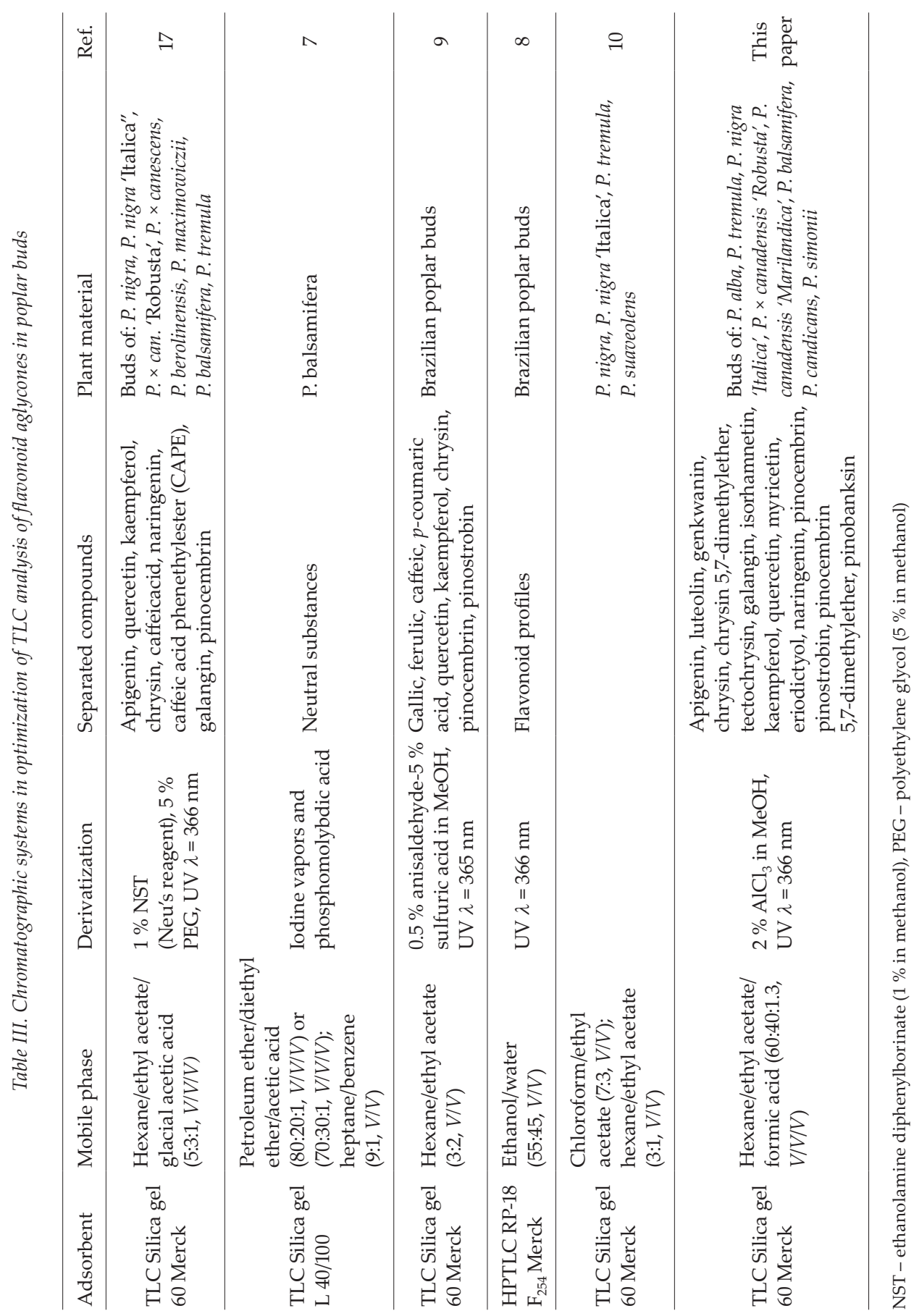




\section{Qualitative screening of poplar bud extracts}

For identification of flavonoids, video-densitometric scanning in UV $(\lambda=366 \mathrm{~nm})$ of $2 \%$ $\mathrm{AlCl}_{3}$-sprayed TLC chromatograms was employed. As a result, 17 standard flavonoids were separated in the range of $h R_{\mathrm{f}}$ from 19 to 90 (Fig. 2). The abovementioned elaborated chromatographic system enabled good resolution of the majority of investigated derivatives of flavones, flavonols and flavanones, and one flavanonol. Satisfactory separation was confirmed by the appropriate values of resolution $\left(R_{\mathrm{s}}\right)$ (Fig. 2). Only two pairs of compounds, flavonols - kaempferol and isorhamnetin, flavones-luteolin and chrysin 5,7-dimethylether, were not fully separated (Figs. 1 and 2). However, identification was possible due to dissimilar fluorescence of the latter pair of flavonoids - luteolin possessed light yellow-green fluorescence while chrysin ether was blue (Fig. 1). The best resolution with $R_{s} \geq 2.0$ was observed for the following flavonoid pairs: tectochrysin-chrysin and apigenin-luteolin (flavones), galangin-kaempferol, isorhamnetin-quercetin and quercetin-myricetin (flavonols) and pinocembrin-pinostrobin (flavanones) (Fig. 2). Until now, separation of only seven (17) or five (9) flavonoids, constituents of poplar buds, was possible by TLC methods (Table III).

The results of TLC separations confirmed that the buds of poplars belonging to sections Aigeiros (Populus $\times$ canadensis 'Marilandica', $P . \times$ canadensis 'Robusta', $P$. nigra 'Italica') and Tacamahaca (P. balsamifera, $P$. candicans, $P$. simonii) are rich in flavonoids while Populi gemmae of section Leuce (P. alba, P. tremula) contained compounds with blue fluorescence, probably

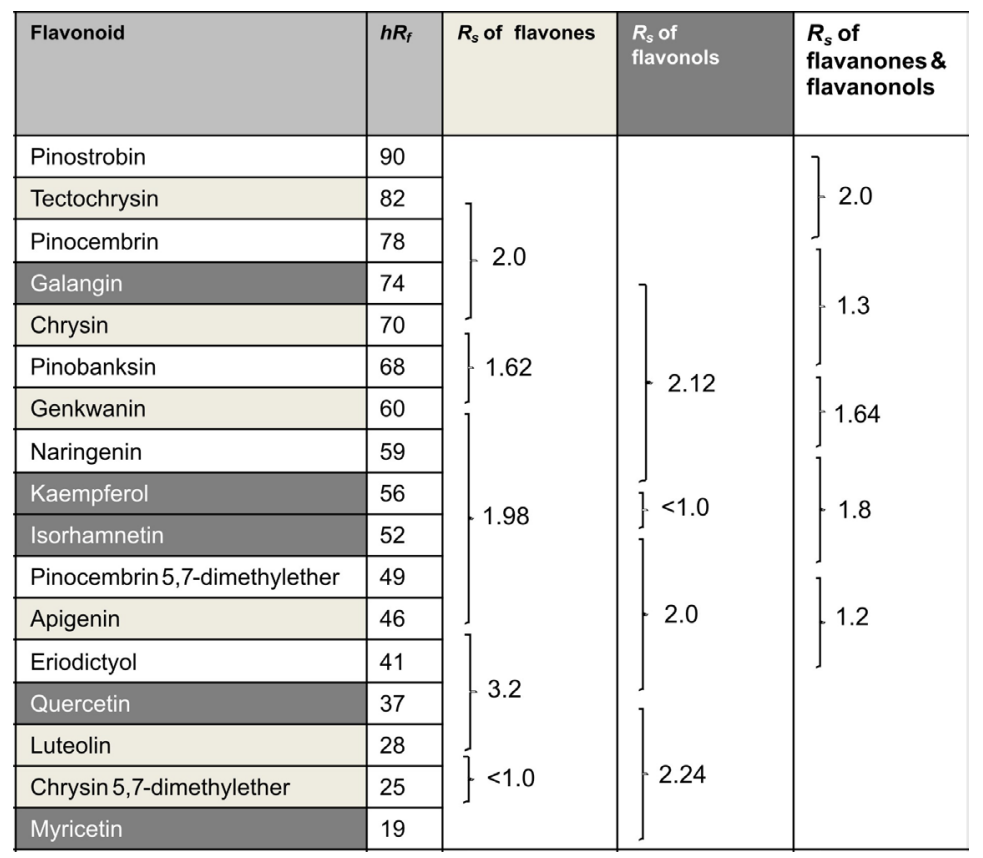

Fig. 2. $R_{\mathrm{s}}$ values of different groups of flavonoids obtained by the elaborated TLC methods.

$R_{s}=z_{2}-z_{1} / 0.5\left(w_{1}+w_{2}\right)\left(z_{1}, z_{2}-\right.$ distances from the start line of the maxima of compound peaks compared in the densitogram; $w_{1}, w_{2}$ - width of analyzed compound peak bases obtained in the densitogram). 
due to cinnamic acid derivatives (6). Similar TLC chromatographic profiles with galangin as the dominating compound showed extracts from the buds of Populus $\times$ canadensis 'Marilandica' and P. simonii, while the TLC chromatogram of $P$. nigra 'Italica' extract was similar to that of $P$. candicans. Comparison of the $h R_{\mathrm{f}}$ values and spot fluorescence at $366 \mathrm{~nm}$ confirmed the presence of the following: pinocembrin in the buds of poplars from sections Aigeiros and Tacamahaca $(6,17)$, pinostrobin in $P$. balsamifera $(7)$, galangin in $P$. $\times$ canadensis 'Robusta' (17), apigenin in P. balsamifera (6), P. × canadensis 'Marilandica' (6), $P . \times$ canadensis 'Robusta' (6) and P. simonii (6), kaempferol in P. × canadensis 'Marilandica' (8), chrysin in P. $\times$ canadensis 'Marilandica' (6), $P$. candicans $(1,6)$ and $P$. simonii (6), pinobanksin in $P$. $\times$ canadensis 'Marilandica' (6) and $P . \times$ canadensis 'Robusta' $(6,17)$, tectochrysin in P. nigra 'Italica' (6) and $P . \times$ canadensis 'Marilandica' (6), and genkwanin in P. balsamifera $(6,18)$ (Fig. 1). The following flavonoids were identified for the first time in poplar buds, namely, pinostrobin in $\mathrm{P} \times \times \mathrm{ca}$ nadensis 'Marilandica', $P . \times$ canadensis 'Robusta', $P$. candicans and $P$. simonii, pinocembrin 5,7-dimethylether in $P$. × canadensis 'Marilandica', $P . \times$ canadensis 'Robusta', $P$. candicans and $P$. nigra 'Italica', chrysin 5,7-dimethylether in P. $\times$ canadensis 'Marilandica' and tectochrysin in $P$. candicans (Fig. 1). Identification of genkwanin and naringenin in the extracts of $P . \times c a-$ nadensis 'Marilandica', $P . \times$ canadensis 'Robusta', P. candicans, $P$. nigra 'Italica' and P. simonii, and identification of pinobanksin in P. balsamifera, P. candicans and P. simonii was difficult due to the high chemical complexity of plant matrices (Fig. 1). Literature data describe the presence of quercetin in the buds of $P$. balsamifera, $P$. nigra and $P . \times$ canadensis $(1,4,18)$, but its identification in the analyzed extracts was impossible due to co-elution with caffeic acid emitting intensive blue fluorescence. The presence of myricetin, luteolin, eriodictyol and isorhamnetin was not observed in any of the analyzed extracts (Fig. 1). Lack of flavonoids was confirmed in the buds of $P$. alba in agreement with literature reports $(6,11,17)$. In contrast to previous studies of poplar buds performed by Wollenweber (6), pinocembrin, chrysin and galangin were not observed in the buds of P. tremula (Fig. 1).

Among the flavonoids identified in the analyzed poplar buds, the contents of two, pinostrobin and pinocembrin, were determined. This was due to their confirmed antioxidant and anti-inflammatory properties, which might be responsible for medicinal efficacy of poplar buds $(14,15)$. Two evaluation modes for quantitative analysis of flavanones, densitometric and videodensitometric, were employed.

\section{Quantitative analysis validation}

Validation parameters of the three elaborated assaying procedures were comparable (Table I).

Linearity of the examined methods was good, with the coefficient of determination $R^{2}>0.0995$. The linear regression parameters - slope and intercept showed the highest values of RSD for densitometric analysis after derivatization with $2 \% \mathrm{AlCl}_{3}$ at $366 \mathrm{~nm}$, both for pinocembrin and pinostrobin determination, whereas the lowest were recorded for the densitometric analysis of pinocembrin at $290 \mathrm{~nm}$ (Table I).

Recovery studies gave good results for both analyzed compounds (Table I). Slightly better recovery results were observed for pinocembrin determination in all tested methods (95.1-95.4 \%) in comparison with pinostrobin analysis (93.3-93.4 \%) (Table I). Relatively low recovery percentages for both compounds could be explained by the influence of extraction effectiveness of other constituents from the plant matrix. 
The instrumental precision RSD of all methods used ranged from 3.2 to $3.7 \%$. The precision of the methods was described by intra- and inter-day assays. The best results of intra-day assays were observed for densitometric determination of pinocembrin at $290 \mathrm{~nm}$ and videodensitometric analysis of pinostrobin at $366 \mathrm{~nm}$ with respective RSDs of 3.3 and $3.1 \%$. The inter-day assays showed the best results for densitometry at $290 \mathrm{~nm}$ for both examined flavanones - RSD 2.8 and $2.3 \%$ (Table I).

Limit of detection $(L O D)$ and limit of quantification $(L O Q)$ values ranged from 0.033 to $0.04 \mathrm{mg} \mathrm{mL}^{-1}$ and from 0.1 to $0.125 \mathrm{mg} \mathrm{mL}^{-1}$, resp., for the analyzed flavanones (Table I).

\section{Assaying of pinocembrin and pinostrobin in poplar buds}

Concentrations of pinocembrin and pinostrobin differed slightly or significantly in some extracts and partly depended on the applied modes of TLC evaluation, with two exceptions, namely, the buds of $P$. balsamifera and $P$. simonii.

Pinocembrin content in the buds of $P$. nigra 'Italica' determined densitometrically, both at $290 \mathrm{~nm}$ and at 310 after derivatization (filter at $370 \mathrm{~nm}$ ), was twice lower compared to videodensitometry $\left(2 \% \mathrm{AlCl}_{3}, 366 \mathrm{~nm}\right.$ ) (Table IV). On the other hand, the pinocembrin content determined densitometrically and videodensitometrically after spraying with $2 \%$ $\mathrm{AlCl}_{3}$ was similar in the majority of analyzed poplar buds (Table IV).

Pinocembrin concentration in the extracts of $P$. $\times$ canadensis 'Marilandica' and P. simonii in the case of densitometry after reaction with $2 \% \mathrm{AlCl}_{3}(366 \mathrm{~nm})$ showed the highest RSD. This was probably due to the presence of additional neighboring compounds (lower $R_{s}$ values) and their concentration (Table IV).

In the majority of poplar extracts, slightly lower amounts of pinostrobin were revealed after densitometric analysis of chromatograms sprayed with $2 \% \mathrm{AlCl}_{3}(310 \mathrm{~nm}$, filter at 370 $\mathrm{nm}$ ) compared to the other methods (Table IV).

Pinostrobin content in P. × canadensis 'Marilandica' buds varied between 0.14 and $0.31 \mathrm{~g}$ per $100 \mathrm{~g}$, depending on the evaluation mode. However, due to high RSD values, the differences were not statistically significant.

Taking into account higher $R_{\mathrm{s}}$ values of pinostrobin than of pinocembrin, the former can be determined by applying all the three methods examined, practically in all analyzed extracts, whereas pinocembrin, possessing lower $R_{\mathrm{s}}$ values, should be determined densitometrically at $290 \mathrm{~nm}$ or videodensitometrically after spraying chromatograms with $2 \%$ $\mathrm{AlCl}_{3}$ at $310 \mathrm{~nm}$ (filter at $370 \mathrm{~nm}$ ).

Contents of pinocembrin and pinostrobin in analyzed poplar buds varied in the range 0.21-1.82 and 0.14-2.24 g per $100 \mathrm{~g}$, resp. (Table IV). The buds from two poplars, $P . \times c a-$ nadensis 'Robusta' (1.82 and $2.23 \mathrm{~g}$ per $100 \mathrm{~g}$ ) and P. balsamifera (1.17 and $2.24 \mathrm{~g}$ per $100 \mathrm{~g}$ ) had higher contents of both compounds than the other taxa (Table IV). Buds of P. nigra 'Italica' and P. candicans had the lowest contents of pinocembrin (0.21 and $0.22 \mathrm{~g}$ per $100 \mathrm{~g}$, resp.), while $P . \times$ canadensis 'Marilandica' contained the lowest concentration of pinostrobin ( $0.14 \mathrm{~g}$ per $100 \mathrm{~g}$ ). No influence of the evaluation mode used on the classification order of Populus buds, as the richest sources of both flavanones, was observed. Contents of pinocembrin and pinostrobin studied in poplar buds were in the previously reported ranges $(3,7,8,12)$ but lower than in poplar resins $(8,13)$. 


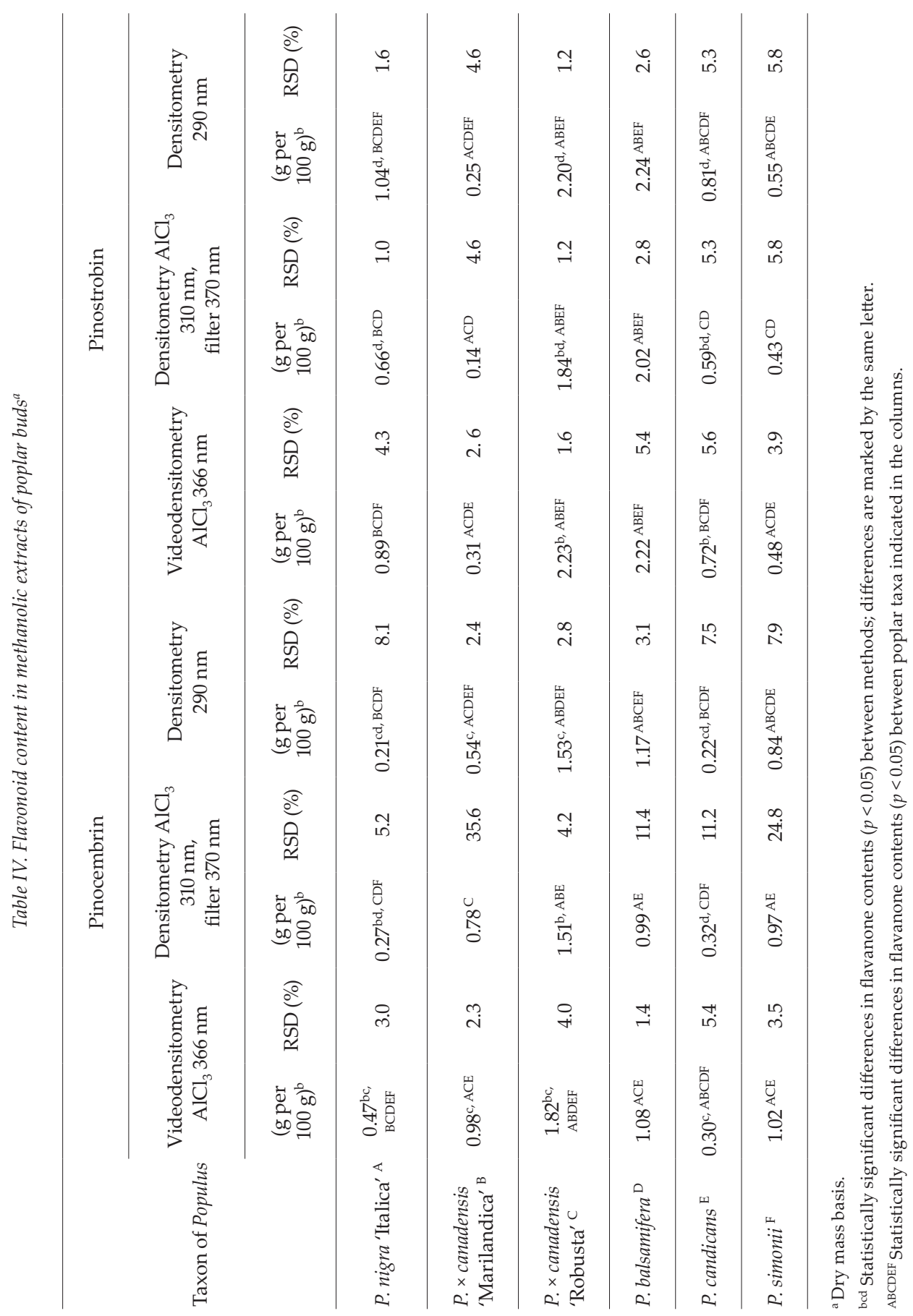




\section{CONCLUSIONS}

The elaborated TLC system enables the resolution of 17 flavonoids and quantitative analysis of two dominant ones, pinocembrin and pinostrobin, in poplar buds. This TLC might be used for qualitative and quantitative analyses of flavonoid aglycones in other plant matrices as well. However, due to the complexity of plant matrices, a comparison of different modes of TLC quantitative evaluation seems to be necessary.

Acknowledgments. - This Project was supported by the Ministry of Science and Higher Education of the Republic of Poland, within the quality - promoting subsidy, under the Leading National Research Centre (KNOW) program for the years 2012-2017.

\section{REFERENCES}

1. P. R. Bradley, British Herbal Compendium, British Herbal Medicine Association, Bournemouth 1992, Vol. 1.

2. German Commission E Monograph, Poplar bud (Populi gemma), February 1, 1990; https://buecher. heilpflanzen-welt.de/BGA-Commission-E-Monographs/0302.htm; last access date January 18, 2018

3. S. Dudonné, P. Poupard, P. Coutière, M. Woillez, T. Richard, J. M. Mérillon and X. Vitrac, Phenolic composition and antioxidant properties of poplar bud (Populus nigra) extract: individual antioxidant contribution of phenolics and transcriptional effect on skin aging, J. Agric. Food Chem. 59 (2011) 4527-4536; https://doi.org/10.1021/jf104791t

4. K. Wang, J. Zhang, S. Ping, Q. Ma, X. Chen, H. Xuan, J. Shi, C. Zhang and F. Hu, Anti-inflammatory effects of ethanol extracts of Chinese propolis and buds from poplar (Populus $\times$ canadensis), J. Ethnopharmacol. 155 (2014) 300-311; https://doi.org/10.1016/j.jep.2014.05.037

5. N. Debbache-Benaida, D. Atmani-Kilani, V. B. Schini-Keirth, N. Djebbli and D. Atmani, Pharmacological potential of Populus nigra extract as antioxidant, anti-inflammatory, cardiovascular and hepatoprotective agent, Asian Pac. J. Trop. Biomed. 3 (2013) 697-704; https://doi.org/10.1016/S22211691(13)60141-0

6. E. Wollenweber, Flavonoidmuster als systematisches Merkmalin der Gattung Populus Biochem. Syst. Ecol. 3 (1975) 35-45.

7. E. V. Isaeva, G. A. Lozhkina and T. V. Ryazanova, A study of the alcohol extract from balsam poplar buds, Russ. J. Bioorg. Chem. 36 (2010) 929-933; https://doi.org/10.1134/S1068162010070228

8. Y. K. Park, S. M. Alencar and C. L. Aguiar, Botanical origin and chemical composition of Brazilian propolis, J. Agric. Food Chem. 50 (2002) 2502-2506; https://doi.org/0.1021/jf011432b

9. J. Adelmann, M. Passos, D. H. Breyer, M. H. Rocha dos Santos, C. Lenz, N. F. Leite, F. M. Lanşas and J. D. Fontana, Exotic flora dependence of an unusual Brazilian propolis: the pinocembrin biomarker by capillary techniques, J. Pharm. Biomed. Anal. 43 (2007) 174-178; https://doi. org/10.1016/j.jpba.2006.07.014

10. V. Bankova, A. Dyulgerov, S. Popov, L. Evstatieva, L. Kuleva, O. Pureb and Z. Zamjansan, Propolis produced in Bulgaria and Mongolia: phenolic compounds and plant origin, Apidologie 23 (1992) 79-85.

11. W. Greenaway, J. May, T. Scaysbrook and F. R. Whatley, Compositions of bud and leaf exudates of some Populus species compared, Z. Naturforsch. C: Biosci. 47 (1992) 329-334; https://doi.org/10.1515/ znc-1992-0602

12. J. Zhang, X. Cao, S. Ping, K. Wang, J. Shi, C. Zhang, H. Zheng and F. Hu, Comparisons of ethanol extracts of Chinese propolis (poplar type) and poplar gums based on the antioxidant activities and molecular mechanism, Evid-Based Complem. Altern. Med. 2015, Article ID 307594 (15 pages); https://doi.org/10.1155/2015/307594 
13. Z. Cui-ping, H. Shuai, W. Wen-ting, P. Shun, S. Xiao-ge, L. Ya-jing and H. Fu-Iiang, Development of high-performance liquid chromatographic for quality and authenticity control of Chinese propolis, J. Food Sci. 79 (2014) C1315-C1322; https://doi.org/10.1111/1750-3841.12510

14. A. Rasul, F. M. Millimouno, W. A. Eltayb, M. Ali, J. Li and X. Li, Pinocembrin: A novel natural compound with versatile pharmacological and biological activities, BioMed. Res. Int. 2013, Article ID 379850 (9 pages); https://doi.org/10.1155/2013/379850

15. N. K. Patel, G. Jaiswal and K. K. Bhutani, A review on biological sources, chemistry and pharmacological activities of pinostrobin, Nat. Prod. Res. 30 (2016) 2017-2027; https://doi.org/10.1080/14786 419.2015.1107556

16. International Conference on Harmonisation of Technical Requirements for Registration of Pharmaceuticals for Human Use, ICH Harmonized Tripartite Guideline, Validation of Analytical Procedures: Text and Methodology Q2(R1), Current Step 4 version, Nov 1996, Geneva, Nov 2005; https://www. ich.org/products/guidelines/quality/article/quality-guidelines.html; last access date January 18, 2018

17. J. Bertrams, M. B. Müller, N. Kunz, D. R. Kammerer and F. C. Stintzing, Phenolic compounds for botanical origin determination of German propolis samples based on TLC and TLC-MS, J. Appl. Bot. Food Qual. 86 (2013) 143-153; https://doi.org/10.5073/JABFQ.2013.086.020

18. J. A. Duke, CRC Handbook of Phytochemical Constituents of GRAS Herbs and Other Economic Plants, CRC Press, Boca Raton (FL) 1992. 